\title{
Biological Stoichiometric Analysis during Substrate Utilization and Secondary Metabolite Production by Non-Saccharomyces Yeasts Using Grape Pomace Extract as Fermentation Medium
}

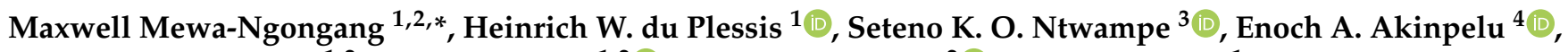 \\ Ucrecia F. Hutchinson ${ }^{1,2}$, Boredi S. Chidi ${ }^{1,2}{ }^{\mathbb{D}}$, Vincent I. Okudoh ${ }^{2}{ }^{\mathbb{D}}$ and Neil P. Jolly ${ }^{1}$ \\ 1 Post-Harvest and Agro-Processing Technologies, ARC Infruitec-Nietvoorbij (The Fruit, Vine and Wine \\ Institute of the Agricultural Research Council), Private Bag X5026, Stellenbosch 7599, South Africa; \\ DPlessisHe@arc.agric.za (H.W.d.P.); hutchinsonu@cput.ac.za (U.F.H.); boredi2002@gmail.com (B.S.C.); \\ jollyn@arc.agric.za (N.P.J.) \\ 2 Bioresource Engineering Research Group (BioERG), Department of Biotechnology, Cape Peninsula University \\ of Technology, P.O. Box 652, Cape Town 8000, South Africa; OkudohV@cput.ac.za \\ 3 School of Chemical and Minerals Engineering, North-West University, Private Bag X1290, \\ Potchefstroom 2520, South Africa; karabo.ntwampe@nwu.ac.za \\ 4 Department of Horticultural Sciences, Cape Peninsula University of Technology, P.O. Box 1906, \\ Bellville 7535, South Africa; biyipelu@gmail.com \\ check for \\ * Correspondence: mewangongangm@cput.ac.za; Tel.: +27-(0)-21-809-3442
} updates

Citation: Mewa-Ngongang, M.; du Plessis, H.W.; Ntwampe, S.K.O.; Akinpelu, E.A.; Hutchinson, U.F.; Chidi, B.S.; Okudoh, V.I.; Jolly, N.P. Biological Stoichiometric Analysis during Substrate Utilization and Secondary Metabolite Production by Non-Saccharomyces Yeasts Using Grape Pomace Extract as Fermentation Medium. Fermentation 2021, 7, 89. https://doi.org/ 10.3390/fermentation7020089

Academic Editor: Antonio Morata

Received: 23 April 2021

Accepted: 11 May 2021

Published: 2 June 2021

Publisher's Note: MDPI stays neutral with regard to jurisdictional claims in published maps and institutional affiliations.

Copyright: () 2021 by the authors. Licensee MDPI, Basel, Switzerland. This article is an open access article distributed under the terms and conditions of the Creative Commons Attribution (CC BY) license (https:// creativecommons.org/licenses/by/ $4.0 /)$.
Abstract: The emerging interest in the search for alternatives to synthetic preservatives has led to various successful research studies exploring the use of yeasts as potential biological control agents and producers of biopreservatives. The findings that yeasts could be used as producers of biopreservatives lacked some engineering considerations regarding cost-effective process design for scale-up, although partial process optimization using renewable agro-waste has been achieved. This study investigated the biological stoichiometry and bioenergetic parameters during yeast growth and secondary metabolites production i.e., biopreservatives from non-Saccharomyces yeasts using grape pomace extract (GPE), a type of agro-waste, as a fermentation medium. This was achieved by reconfirming the optimum production conditions previously found for Candida pyralidae Y1117, Pichia kluyveri Y1125, and Pichia kluyveri Y1164 in GPE broth as a fermentation medium, conditions under which a high amount of yeast cells were obtained. High-density cell cultures were produced, from which the yeast cell pellets were harvested, dried, and combusted for the determination of elemental analysis, heat of combustion, biological stoichiometry, and bioenergetic parameters. This work generated biological stoichiometric models and bioenergetics information that could assist in the design of yeast biochemical conversion system when GPE is used as fermentation medium, thereby, addressing the biochemical engineering aspects that were lacking in a previous biopreservative production study using Candida pyralidae Y1117, Pichia kluyveri Y1125, and Pichia kluyveri Y1164.

Keywords: biopreservatives; biological stoichiometry; bioenergetics; grape pomace extract; yeasts

\section{Introduction}

The potential of yeasts as biological control agents and as producers of biopreservatives has been established by several independent studies [1-5]. However, those studies have been carried out in refined media with fewer biochemical engineering aspects for bioreactor designs and performance assessment for high-scale production. Recently, grape pomace extract (GPE) was explored as a readily available and cheap fermentation medium for the production of biopreservatives from yeasts [6]. The feasibility of a bioprocess engineering system and the related physiological conditions under which bioreactions can occur would only be possible by studying the biological thermodynamics of the process, in particular when considering industrial-scale production. This has not yet been applied 
extensively in biological processes [7]. In addition, yield parameters can also be estimated during fermentation in order to assess the material and energy requirements in relation to the economic viability of any intended biological process [8-10]. Studying biological stoichiometry is also vital for establishing a control data set for system design and process control for the conversion of substrate by yeast, which is linked to secondary metabolite production using any renewable carbon source such as GPE as a fermentation medium. Akinpelu et al. [11] reported on the stoichiometric analysis of microbial growth and related yields for some biological processes. The production requirements in a bioreactor system in relation to the conversion of the growth-controlling substrate for extracellular compound production can be determined by the stoichiometric coefficients and bioenergetic analysis, which can better assist in elucidating the feasibility of a bioprocess system being designed and set a benchmark for other similar processes.

This can be achieved using conservation of mass, whereby microbial growth models can be applied for system parameter analysis. Several methods, such as that of halfreactions or irregularities can be used to evaluate the stoichiometric requirements of any conversion that takes place during microbial growth and bioproduct formation $[9,11]$. During the process of microbial conversion of substrates to extracellular compounds, catabolic and anabolic reactions occur. In the catabolic phase, the primary growth-controlling substrate such as glucose is broken down, and a portion of the catabolic product is then used in the anabolic phase for the synthesis of new biomass [9]. Table 1 depicts all the different equations that can be used to determine the parameters described above.

Table 1. Microbial growth parameters and the related models that describe the stoichiometric parameter analysis [9].

\begin{tabular}{cc}
\hline Parameter & Equation \\
\hline Biological Stoichiometry & $\frac{1}{Y_{\frac{X}{S}}} S+Y_{\frac{A}{X}} A+Y_{\frac{N}{X}} N S \rightarrow X+Y_{\frac{P}{X}} P+Y_{\frac{C}{X}} C O_{2}$ \\
\hline Catabolic Reaction & $S+Y_{A}^{c a t} A \rightarrow Y_{P}^{c a t} P+Y_{C}^{c a t} C O_{2}\left(\Delta G_{c a t}^{0}\right)$ \\
\hline Anabolic Reaction & $Y_{p}^{a n a} P+Y_{C}^{a n a} C O_{2}+Y_{N}^{a n a} N S \rightarrow X+Y_{A}^{a n a} A\left(\Delta G_{\text {ana }}^{0}\right)$ \\
\hline
\end{tabular}

$S, A, N S, X$, and $P$ represent the substrate (energy source), electron acceptor, nitrogen source, dry biomass, and reduced electron acceptor, respectively.

Once stoichiometric requirements of a biological process have been determined, it is imperative to establish the energy requirements for the system. As substrates are being utilized as electron donors, accounting for the energy requirements means that parameters such as enthalpy of formation $\left(\Delta H_{f}^{O}\right)$, Gibbs energy $\left(\Delta G_{f}^{O}\right), \mathrm{c}$ and heat of reaction $\left(\Delta H_{R X}^{O}\right)$ are to be considered, with the Gibbs energy being the main driving force $[7,9,12,13]$. Therefore, the values for $\Delta G, \Delta H$, and $\Delta S$ can be estimated using Equation (1) [11].

$$
\Delta G=\Delta H-T \Delta S
$$

With $\Delta G, \Delta H$, and $\Delta S$ representing the Gibbs energy, enthalpy, and entropy changes, respectively.

Practically, this means that, for a bioreaction, experimental values for the formation of cells and the related heat of combustion are to be determined using Equation (2) [11].

$$
\Delta H_{C}^{\text {cell }}\left(\frac{K J}{m o l}\right)=\Delta H_{\text {cal }}^{\text {cell }}\left(\frac{K J}{g}\right) X M_{X}
$$

with $\Delta H_{C}^{c e l l}, \Delta H_{c a l}^{c e l l}$, and $M_{X}$, representing the heat of combustion, calorimetric enthalpy of formation, and the mass of $1 \mathrm{C}$-mol of the dried biomass, respectively. 
Once the heat of formation of biomass is obtained, the heat of reaction, as the result of the biosynthesis of $1 \mathrm{C}$-mol of biomass, can be estimated using Hess's law-see Equation (3):

$$
\Delta H_{R X}^{O}=\sum n\left(\Delta H_{\text {products }}\right)-\sum n\left(\Delta H_{\text {reactants }}\right)
$$

where $n$ represents the respective stoichiometric molar coefficients.

The highest level of substrate conversion leading to the production of extracellular compounds, i.e., biopreservatives, occurred during the exponential growth phase of the yeast as described by Mewa-Ngongang et al. [14]. This study aimed to generate benchmarking biological stoichiometric and bioenergetics parameters during substrate utilization for growth of non-Saccharomyces yeasts and production of secondary metabolites using GPE, i.e., an agro-waste, as a fermentation medium, and to provide a set of requirements for the design of a biochemical conversion system. Such an assessment is scantly available in the literature, and in the future, biochemical processes could possibly use extracts from agro-waste as fermentation medium.

\section{Materials and Methods}

\subsection{Microorganisms Selection, Culture Condition, and Inoculum Preparation}

Candida pyralidae Y1117, Pichia kluyveri Y1125, and Pichia kluyveri Y1164 were selected based on their biopreservative production potential $[6,14]$. However, biological stoichiometric parameters, which are required for an engineering process design, were not found in the literature. Dekkera bruxellensis, a major spoilage organism for beverages, was used as the sensitive organism in the growth inhibition assay [6]. The yeast inoculums of C. pyralidae Y1117, P. kluyveri Y1125, and P. kluyveri Y1164 were prepared firstly by culturing on the grape pomace agar (GPA) for 2 days at $28{ }^{\circ} \mathrm{C}$. The yeast cells were prepared by transferring a wire loop full of the culture into $5 \mathrm{~mL}$ of Yeast Peptone Dextrose (YPD) broth (Sigma Aldrich, South Africa) subsequent to incubation at $28{ }^{\circ} \mathrm{C}$ for $24 \mathrm{~h}$. From the $24 \mathrm{~h}$ old yeast cultures, a volume of $1 \mathrm{~mL}$ was transferred to $150 \mathrm{~mL}$ sterile grape pomace extract broth (GPEB) diluted to $100 \mathrm{~g} \mathrm{~L}^{-1}$ total sugar using sterile distilled water. The yeast-assimilable nitrogen content of the $100 \mathrm{~g} \mathrm{~L}^{-1}$ total sugar GPEB was $0.074 \mathrm{~g} \mathrm{~L}^{-1}$. The inoculated GPEB was subjected to incubation at $25^{\circ} \mathrm{C}$ with agitation at $150 \mathrm{rpm}$, using a rotary shaker (LM-53OR, RKC Instrument Inc., Ohta-ku Tokyo, Japan) for $24 \mathrm{~h}$ [14].

\subsection{Medium Preparation, Fermentation Condition, and Confirmation of Growth Inhibition Activity}

An agro-waste-based medium using grape pomace extract (GPE) was prepared and used. Wet Chenin blanc grape pomace was collected in plastic buckets. The wet pomace was then further pressed at an increased pressure of up to 2 bars in order to extract the remaining juice, which was analyzed for sugar and nitrogen contents including $\mathrm{pH}$. Total sugar and yeast-assimilable nitrogen concentrations of 150 and $0.136 \mathrm{~g} \mathrm{~L}^{-1}$, respectively, and a $\mathrm{pH}$ of 3 were prepared. The fermentation for C. pyralidae Y1117, P. kluyveri Y1125, and P. kluyveri Y1164 was conducted as reported elsewhere [6]. Each yeast was cultured in a $4 \mathrm{~L}$ Erlenmeyer flask containing 1.3 L GPEB with three replicates. The growth inhibition activity of the crude biopreservatives from the three yeasts was evaluated and quantified using a plate assay method $[6,14]$. When D. bruxellensis was used as the sensitive organism, the concept of volumetric zone of inhibition (VZI) as reported by Mewa-Ngongang et al. [14] was used for growth inhibition activity quantification.

\subsection{Biomass Preparation and Elemental Analysis}

After fermentation, the yeast cultures were harvested by centrifugation at $10,000 \mathrm{rpm}$ for $10 \mathrm{~min}$ at $4{ }^{\circ} \mathrm{C}$. The resulting biomass pellets were washed three times with sterile distilled water and dried in a Duran ${ }^{\circledR}$ vacuum desiccator (DURAN Group GmbH, Germany). The process was repeated until a considerable amount of $10 \mathrm{~g}$ biomass was obtained. The wet cell pellets of C. pyralidae Y1117, P. kluyveri Y1125, and P. kluyveri Y1164 were picked 
using a sterile spatula and placed into sterile glass Petri dishes. The cultures were then placed in an oven dryer set at $70^{\circ} \mathrm{C}$ for $8 \mathrm{~h}$ and thereafter put in a desiccator at $28^{\circ} \mathrm{C}$ for 3 days. Each plate was weighed twice a day to assess the fluid loss and to attain a constant weight. To remove residual moisture, the contents of the plates were transferred to sterile glass beakers and further dried in an oven at $50{ }^{\circ} \mathrm{C}$ until the weight became constant. The analysis of carbon $(\mathrm{C})$, hydrogen $(\mathrm{H})$, nitrogen $(\mathrm{N})$, and sulfur $(\mathrm{S})$ in the dried biomass was performed in three replicates for each yeast. The fraction corresponding to the percentage of oxygen was that of the remaining fraction after the sum of CHNS percentages was subtracted from 100 .

\subsection{Heat of Combustion Determination}

An e2k Bomb calorimeter (Digital Data Systems Pty Ltd., Randburg, South Africa) was used to determine the heat of combustion of the dried biomass. The principle of general combustion was used, whereby the analyzer was set to combust the samples in three replicates in the presence of oxygen to form $\mathrm{CO}_{2}, \mathrm{H}_{2} \mathrm{O}$, and $\mathrm{N}_{2}$. The products of combustion were then separated using a gas chromatograph and then further analyzed by a thermal conductivity detector. The peaks obtained, corresponding to each compound (product of combustion), were integrated, and then the percentages of $\mathrm{C}, \mathrm{H}, \mathrm{O}, \mathrm{N}$, and $\mathrm{S}$ were calculated. Table 2 presents the heat of formation of reference compounds that were used to determine the heat of combustion for the dried biomass.

Table 2. Heat of formation at $298.15 \mathrm{~K}$ and $1 \mathrm{~atm}(101,325 \mathrm{kPa})$ of reference compounds used for the heat of combustion calculation during this study [12].

\begin{tabular}{ccc}
\hline Substance & Formula & $\Delta H_{f}^{O}(\mathbf{K J} / \mathbf{m o l})$ \\
\hline Glucose & $\mathrm{C}_{6} \mathrm{H}_{12} \mathrm{O}_{6(a q)}$ & -1263.07 \\
Ammonia & $\mathrm{NH}_{3(a q)}$ & -80.29 \\
Oxygen & $\mathrm{O}_{2}(a q)$ & -12.09 \\
Water & $\mathrm{H}_{2} \mathrm{O}_{(l)}$ & -285.83 \\
\hline
\end{tabular}

\subsection{Determination of Stoichiometric Molar Coefficients}

The biomass yield, based on substrate consumption, was calculated to determine the number of moles of glucose utilized to form a yeast cell. A unit carbon per mole of glucose molecular weight (MW) of each yeast was then determined, which yielded the equations listed below, Equations (4)-(6), which were balanced using the law of conservation of mass based on the balances of the elemental molecular constituents.

C. pyralidae $Y 1117$

$$
1.8997 \mathrm{C}_{6} \mathrm{H}_{12} \mathrm{O}_{6(a q)}+a \mathrm{O}_{2(a q)}+b \mathrm{NH}_{3(a q)}+c \mathrm{SO}_{4(a q)}^{2-}+d \mathrm{H}_{(a q)}^{+} \rightarrow \mathrm{CH}_{1.906} \mathrm{~N}_{0.149} \mathrm{O}_{0.805} \mathrm{~S}_{0.003}(c e l l)+e \mathrm{CO}_{2(a q)}+f \mathrm{H}_{2} \mathrm{O}_{(l)}
$$

P. kluyveri $Y 1125$

$$
1.9293 \mathrm{C}_{6} \mathrm{H}_{12} \mathrm{O}_{6(a q)}+a \mathrm{O}_{2(a q)}+b \mathrm{NH}_{3(a q)}+c \mathrm{SO}_{4(a q)}^{2-}+d \mathrm{H}_{(a q)}^{+} \rightarrow \mathrm{CH}_{1.891} \mathrm{~N}_{0.132} \mathrm{O}_{0.833} \mathrm{~S}_{0.003}(c e l l)+e \mathrm{CO}_{2(a q)}+f \mathrm{H}_{2} \mathrm{O}_{(l)}
$$

\section{P. kluyveri Y1164}

$$
3.043 \mathrm{C}_{6} \mathrm{H}_{12} \mathrm{O}_{6(a q)}+a \mathrm{O}_{2(a q)}+b \mathrm{NH}_{3(a q)}+c \mathrm{CS}_{4(a q)}^{2-}+d \mathrm{H}_{(a q)}^{+} \rightarrow \mathrm{CH}_{1.868} \mathrm{~N}_{0.146} \mathrm{O}_{0.698} \mathrm{~S}_{0.003}(c e l l)+e \mathrm{CO}_{2(a q)}+f \mathrm{H}_{2} \mathrm{O}_{(l)}
$$

\section{Results}

\subsection{Confirmation of Growth Inhibition Activity}

Based on previous research involving the yeasts selected for this work, it was deemed necessary to confirm the growth inhibition activity of the crude biopreservatives produced to ascertain the efficacy of the yeasts as biopreservative producers as previously reported [6]. 
The growth inhibition activities resulting from the three crude biopreservatives were indeed prominent, with a VZI of $0.78,0.40$, and 0.35 L VZI.mL ${ }^{-1}$ BCU for C. pyralidae Y1117, P. kluyveri Y1125, and P. kluyveri Y1164, respectively (Figure 1).

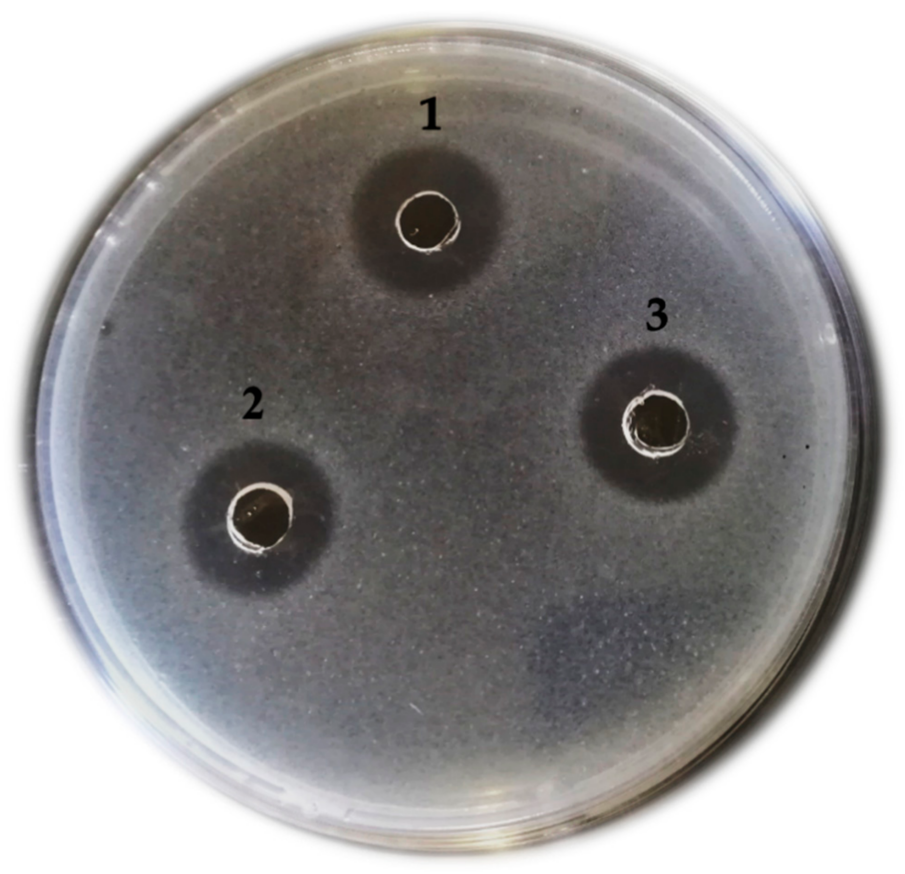

Figure 1. Growth inhibition activity of crude biopreservatives from Candida pyralidae Y1117 (1), Pichia kluyveri Y1125 (2), and P. kluyveri Y1164 (3) when Dekkera bruxellensis was used as the sensitive organism on a grape pomace extract medium.

\subsection{Biomass Elemental Analysis}

Table 3 shows the results of the elemental analysis of the dried cells mass belonging to C. pyralidae Y1117, P. kluyveri Y1125, and P. kluyveri Y1164. Similar trends were observed for all three biopreservative-producing yeasts. Primarily, from the percentages of the elements analyzed, the averaged molecular weight and the unit carbon values (Table 3) were determined. The strain P. kluyveri Y1164 was the yeast with the highest carbon and hydrogen content, $44.149 \%$ and $6.871 \%$, respectively, while C. pyralidae Y1117 and P. kluyveri Y1125 had a carbon content of $41.435 \%$ and $41.157 \%$, respectively, and a hydrogen content of $6.582 \%$ and $6.484 \%$, respectively. The nitrogen content of the dried biomass was similar, i.e., $7.200 \%, 6.333 \%$, and $7.530 \%$, for C. pyralidae Y1117, P. kluyveri Y1125, and P. kluyveri Y1164, respectively. These results are comparable to what was observed by Akinpelu et al. [11] and Battley [12] in different studies. Previous studies also demonstrated that the contribution of other constituents including metal ions was negligible, thus not affecting the formulation of the MW [8,12]; however, their presence can have an effect not only on the composition in relation to the oxygen fraction of the biomass but also on the biomass performance. 
Table 3. Elemental analysis, average molecular weight, and unit carbon mole of Candida pyralidae Y1117, Pichia kluyveri Y1125, and P. kluyveri Y1164 during biopreservation compound production using grape pomace extract as fermentation medium. The values presented in the table are the average of three replicates.

\begin{tabular}{|c|c|c|c|c|c|c|}
\hline Yeast & & [C] & {$[\mathrm{H}]$} & {$[\mathrm{N}]$} & [O] & [S] \\
\hline \multirow{3}{*}{$\begin{array}{c}\text { C. pyralidae } \\
\text { Y1117 }\end{array}$} & $\%$ & 41.435 & 6.582 & 7.200 & 44.501 & 0.282 \\
\hline & Average MW & 3.453 & 6.582 & 0.514 & 2.781 & 0.009 \\
\hline & Unit-carbon & 1.000 & 1.906 & 0.149 & 0.805 & 0.003 \\
\hline \multirow{3}{*}{$\begin{array}{l}\text { P. kluyveri } \\
\text { Y1125 }\end{array}$} & $\%$ & 41.157 & 6.484 & 6.333 & 45.713 & 0.313 \\
\hline & Average MW & 3.430 & 6.484 & 0.452 & 2.857 & 0.010 \\
\hline & Unit-carbon & 1.000 & 1.891 & 0132 & 0.833 & 0.003 \\
\hline \multirow{3}{*}{$\begin{array}{l}\text { P. kluyveri } \\
\text { Y1164 }\end{array}$} & $\%$ & 44.149 & 6.871 & 7.530 & 41.104 & 0.346 \\
\hline & Average MW & 3.679 & 6.871 & 0.538 & 2.569 & 0.011 \\
\hline & Unit-carbon & 1.000 & 1.868 & 0.146 & 0.698 & 0.003 \\
\hline
\end{tabular}

\subsection{Determination of Stoichiometric Molar Coefficients}

The stoichiometric molar coefficients for C. pyralidae Y1117, P. kluyveri Y1125, and P. kluyveri Y1164 are listed in Table 4. The MW of a unit carbon mole of each yeast was calculated from each of the elemental formulas. It was found that the MW of C. pyralidae

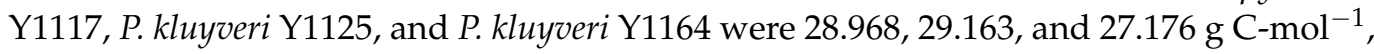
respectively, which is in agreement with what has been reported by Akinpelu et al. [11]. The similarities of these findings with those of the published literature could be attributed to the use of renewable macro- and micronutrient-rich sources from agro-waste [11].

Table 4. Empirical, elemental formula and molecular weight of unit carbon mole of C. pyralidae Y1117, P. kluyveri Y1125, and P. kluyveri Y1164 during yeast growth and secondary metabolite production, i.e., biopreservatives using grape pomace extract as a fermentation medium.

\begin{tabular}{cccc}
\hline & C. pyralidae Y1117 & P. kluyveri Y1125 & P. kluyveri Y1164 \\
\hline Empirical Formula & $C_{3.454} H_{6.585} N_{0.514} \mathrm{O}_{2.78} S_{0.009}$ & $C_{3.453} H_{6.484} N_{0.452} \mathrm{O}_{2.857} S_{0.010}$ & $C_{3.679} H_{6.871} N_{0.538} \mathrm{O}_{2.569} S_{0.011}$ \\
\hline Elemental Formula & $\mathrm{CH}_{1.906} \mathrm{~N}_{0.149} \mathrm{O}_{0.805} S_{0.003}$ & $\mathrm{CH}_{1.891} N_{0.132} \mathrm{O}_{0.833} S_{0.003}$ & $\mathrm{CH}_{1.868} N_{0.146} \mathrm{O}_{0.698} S_{0.003}$ \\
\hline $\begin{array}{c}\text { MW of Unit Carbon } \\
\text { (g/C-mol) }\end{array}$ & 28.968 & 29.163 & 27.176 \\
\hline
\end{tabular}

After the unit carbon molecular weights for the yeasts, i.e., C. pyralidae Y1117, P. kluyveri Y1125, and P. kluyveri Y1164, were determined, the biological stoichiometric equations were derived and balanced by determining the stoichiometric coefficients ( $a-f)$ using the conservation of mass approach (Table 5). The models used to represent and describe C. pyralidae Y1117, P. kluyveri Y1125, and P. kluyveri Y1164 metabolism per unit carbon mol during biochemical conversion of substrate for growth and secondary metabolite production i.e., biopreservatives using GPE as fermentation medium, are also presented in Table 5. The model equations were classified into three steps corresponding to the catabolic, anabolic, and metabolic reactions. Comparing these models to those reported in the literature, it was observed that there were some similarities, although these equations were generated from a different carbon source to those previously used; however, some of the processes were carried out using refined glucose and ammonia as energy sources for the fermentations. It was also observed that the three metabolic reaction models corresponding to the three biopreservative-producing yeasts were distinct from each other, which also justified the need to understand the different biochemical conversion ratios. During biochemical conversion, P. kluyveri Y1164 utilized more glucose than C. pyralidae Y1117 and P. kluyveri Y1125. The growth inhibition activity, illustrated by the VZI values [6], as the result of yeast growth and secondary metabolite production, i.e., the biopreservation compound concentrations, in the crude was found to be lower for P. kluyveri Y1164 than those for C. pyralidae Y1117 and P. kluyveri Y1125. The biological 
stoichiometric results showed an interesting interplay in this regard, whereby the growth model generated for P. kluyveri Y1164 demonstrated the need for more dissolved oxygen in comparison to other yeasts. Additionally, less biomass was generated, albeit with more water formation in product metabolism of P. kluyveri Y1164, which can explain the VZI variations observed. Therefore, the generated data reported in this study can be useful for system design for biopreservation compound production using GPE or a similar agrowaste medium, depending on the source, for fermentation systems. Additionally, these models (Tables 5 and 6 ) can be useful to simulate both mass and energy relationships for bioprocess simulation packages currently in development without the need for laboratory experimentation.

Table 5. Catabolism and anabolism equations for biopreservation compound production per unit glucose used by $C$. pyralidae $\mathrm{Y} 1117$, P. kluyveri $\mathrm{Y} 1125$, and P. kluyveri $\mathrm{Y} 1164$ using grape pomace extracts as fermentation medium.

\section{C. pyralidae Y1117}

Catabolism:

$$
\begin{gathered}
\mathrm{C}_{6} \mathrm{H}_{12} \mathrm{O}_{6(a q)}+6 \mathrm{O}_{2(a q)} \rightarrow 6 \mathrm{H}_{2} \mathrm{O}_{(l)}+6 \mathrm{CO}_{2(a q)} \\
\text { Anabolism: } \\
0.383 \mathrm{H}_{2} \mathrm{O}_{(l)}+0.526 \mathrm{CO}_{2(a q)}+0.078 \mathrm{NH}_{3(a q)}+0.002 \mathrm{SO}_{4(a q)}^{2-}+0.003 \mathrm{H}_{(a q)}^{+} \rightarrow \\
0.526 \mathrm{CH}_{1.906} \mathrm{~N}_{0.149} \mathrm{O}_{0.805} \mathrm{~S}_{0.003}(\mathrm{cell})+0.509 \mathrm{O}_{2} \\
\text { Metabolism: } \\
\mathrm{C}_{6} \mathrm{H}_{12} \mathrm{O}_{6(a q)}+0.078 \mathrm{NH}_{3(a q)}+5.491 \mathrm{O}_{2(a q)}+0.002 \mathrm{SO}_{4}^{2-}+0.003 \mathrm{H}^{+} \rightarrow \\
5.419 \mathrm{CO}_{2(a q)}+5.617 \mathrm{H}_{2} \mathrm{O}_{(l)}+0.526 \mathrm{CH}_{1.906} \mathrm{~N}_{0.149} \mathrm{O}_{0.805} \mathrm{~S}_{0.003}(\mathrm{cell})
\end{gathered}
$$

\section{P. kluyveri Y1125}

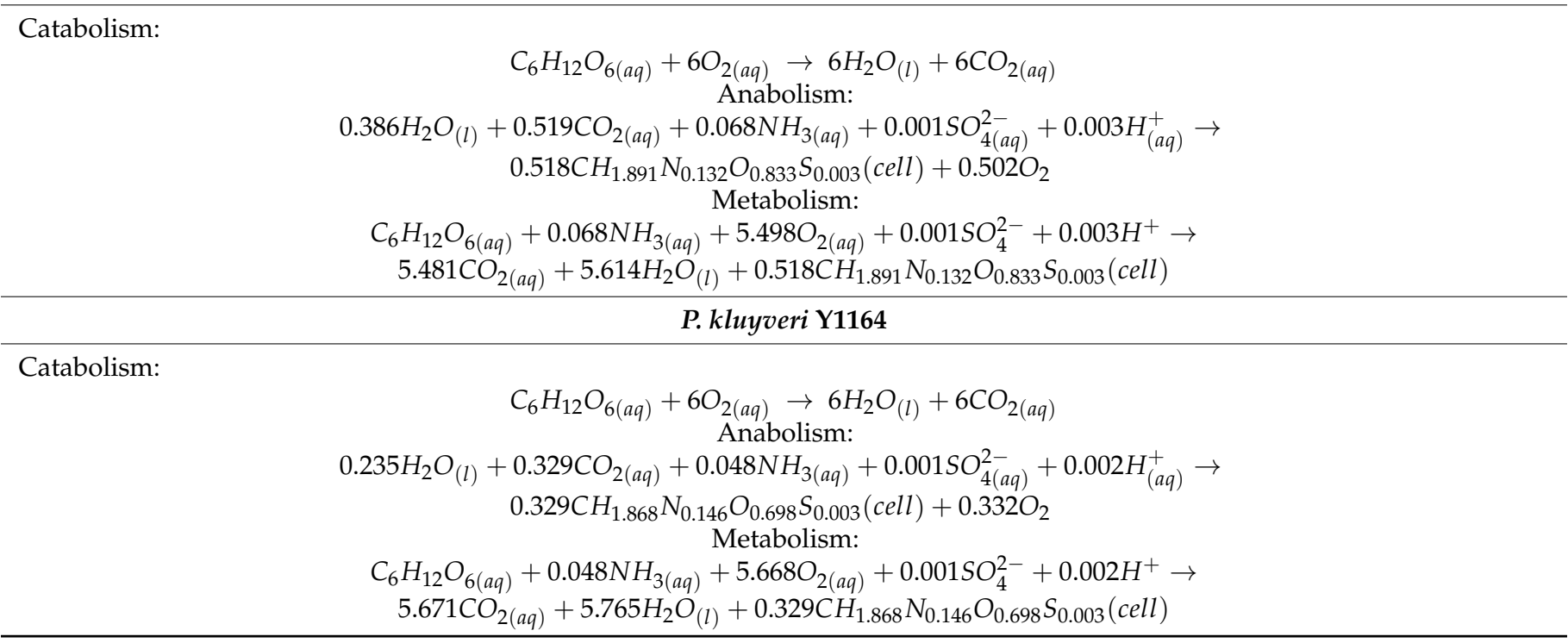

Table 6. Microbial growth equations of C. pyralidae Y1117, P. kluyveri Y1125, and P. kluyveri Y1164 during biopreservation compound production using grape pomace extract as fermentation medium, derived and balanced by determining the stoichiometric coefficients using the conservation of mass approach.

C. pyralidae $\mathrm{Y} 1117$

$1.929 \mathrm{C}_{6} \mathrm{H}_{12} \mathrm{O}_{6(a q)}+10.431 \mathrm{O}_{2(a q)}+0.149 \mathrm{NH}_{3(a q)}+0.003 \mathrm{SO}_{4(a q)}^{2-}+0.006 \mathrm{H}_{(a q)}^{+} \rightarrow$ $\mathrm{CH}_{1.906} \mathrm{~N}_{0.149} \mathrm{O}_{0.805} \mathrm{~S}_{0.003}($ cell $)+10.398 \mathrm{CO}_{2(a q)}+10.672 \mathrm{H}_{2} \mathrm{O}_{(l)}$ 
Table 6. Cont.

\begin{tabular}{c}
\hline P. kluyveri $\mathrm{Y} 1125$ \\
\hline $1.900 \mathrm{C}_{6} \mathrm{H}_{12} \mathrm{O}_{6(a q)}+10.608 \mathrm{O}_{2(a q)}+0.132 \mathrm{NH}_{3(a q)}+0.003 \mathrm{SO}_{4(a q)}^{2-}+0.006 \mathrm{H}_{(a q)}^{+} \rightarrow$ \\
$\mathrm{CH}_{1.891} \mathrm{~N}_{0.132} \mathrm{O}_{0.833} \mathrm{~S}_{0.003}($ cell $)+10.576 \mathrm{CO}_{2(a q)}+10.831 \mathrm{H}_{2} \mathrm{O}_{(l)}$ \\
\hline P. kluyveri $\mathrm{Y} 1164$ \\
\hline $3.043 \mathrm{C}_{6} \mathrm{H}_{12} \mathrm{O}_{6(a q)}+17.249 \mathrm{O}_{2(a q)}+0.146 \mathrm{NH}_{3(a q)}+0.003 \mathrm{SO}_{4(a q)}^{2-}+0.006 \mathrm{H}_{(a q)}^{+} \rightarrow$ \\
$\mathrm{CH}_{1.868} \mathrm{~N}_{0.146} \mathrm{O}_{0.698} \mathrm{~S}_{0.003}($ cell $)+17.258 \mathrm{CO}_{2(a q)}+17.543 \mathrm{H}_{2} \mathrm{O}_{(l)}$ \\
\hline
\end{tabular}

\subsection{Bioenergetic Parameters Determination}

The combustion equations were used to determine the bioenergetic parameters for each of the biocontrol yeasts—see Table 7.

Table 7. The combustion equations used for the calculation of energy requirements during biochemical conversion of substrate for growth and secondary metabolite production (biopreservatives) by C. pyralidae Y1117, P. kluyveri Y1125, and $P$. kluyveri Y1164 using grape pomace extract as fermentation medium.

\begin{tabular}{cl}
\hline Yeast & \multicolumn{1}{c}{ Combustion Equations } \\
\hline C. pyralidae $\mathrm{Y} 1117$ & $\mathrm{CH}_{1.906} \mathrm{~N}_{0.149} \mathrm{O}_{0.805} \mathrm{~S}_{0.003}($ cell $)+1.475 \mathrm{O}_{2} \rightarrow \mathrm{CO}_{2(g)}+0.95 \mathrm{H}_{2} \mathrm{O}_{(l)}+0.0745 \mathrm{~N}_{2(g)}+0.003 \mathrm{H}_{2} \mathrm{~S}_{(g)}$ \\
\hline P. kluyveri $\mathrm{Y} 1125$ & $\mathrm{CH}_{1.891} \mathrm{~N}_{0.132} \mathrm{O}_{0.833} \mathrm{~S}_{0.003}($ cell $)+1.055 \mathrm{O}_{2} \rightarrow \mathrm{CO}_{2(g)}+0.942 \mathrm{H}_{2} \mathrm{O}_{(l)}+0.066 \mathrm{~N}_{2(g)}+0.003 \mathrm{H}_{2} \mathrm{~S}_{(g)}$ \\
\hline P. kluyveri $\mathrm{Y} 1164$ & $\mathrm{CH}_{1.868} \mathrm{~N}_{0.146} \mathrm{O}_{0.698} \mathrm{~S}_{0.003}($ cell $)+1.116 \mathrm{O}_{2} \rightarrow \mathrm{CO}_{2(g)}+0.931 \mathrm{H}_{2} \mathrm{O}_{(l)}+0.066 \mathrm{~N}_{2(g)}+0.003 \mathrm{H}_{2} \mathrm{~S}_{(\mathrm{g})}$ \\
\hline
\end{tabular}

Thermodynamic parameters as analyzed in a bomb calorimeter, particularly the heat of combustion $\left(\Delta H_{c}^{c e l l}\right)$ for the dried C. pyralidae Y1117, P. kluyveri Y1125, and $P$. kluyveri Y1164 biomass, was determined to be $12.29,17.98$, and $17.09 \mathrm{~kJ} / \mathrm{g}$, respectively. Furthermore, the experimental enthalpy of combustion for the three biocontrol yeasts was found to be $-471.89 \mathrm{~kJ} / \mathrm{C}$-mol for C pyralidae Y1117, $-524.35 \mathrm{~kJ} / \mathrm{C}-\mathrm{mol}$ for P. kluyveri Y1125, and $-464.44 \mathrm{~kJ} / \mathrm{C}$-mol for P. kluyveri Y1164. The variations in bioenergetics were calculated using the values obtained from the bomb calorimeter and the thermodynamic properties found in the literature and listed in Table 2. Thornton's rule and approach (Equation (7)) was used-a technique that is similar to the approach reported in Akinpelu et al. [11] and Thornton [15].

$$
\Delta H_{c}^{o}=-107.9 \frac{k j}{e q} X(\text { eq. transferred to oxygen during bomb calorimetric combustion })
$$

The key thermodynamic parameters of interest were enthalpy of biomass formation $\Delta H_{f}^{c e l l}$, heat of reaction $\Delta H_{R X}^{O}$, and the entropy changes $\Delta S_{R X}^{O}$-see Table 8 . The heat of

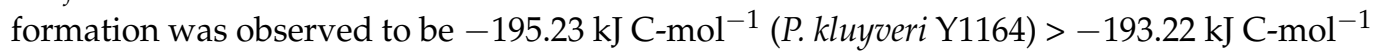
(C. pyralidae Y1117) > -138.46 kJ C-mol ${ }^{-1}$ (P. kluyveri Y1125). Overall, a higher exothermic value translated to higher values for yeast growth during fermentation, which also explains the yield values obtained during the kinetic study by Mewa-Ngongang et al. [6]. Furthermore, the biomass formation was hypothetically spontaneous for the system developed using GPE. Entropy values were determined, i.e., $-0.45,-0.21$, and $-0.53 \mathrm{~kJ} \mathrm{~K} \mathrm{~K}^{-1} \mathrm{C}-\mathrm{mol}$ for C. pyralidae Y1117, P. kluyveri Y1125, and P. kluyveri Y1164, respectively, translating to an entropically driven process. Based on previous studies on bioenergetics, the values obtained for the bioenergetic parameters studied and reported herein are in agreement with what has been reported elsewhere $[7,8,11,13]$. 
Table 8. Thermodynamic parameters during biochemical conversion of substrate and secondary metabolite production (biopreservatives) by C. pyralidae Y1117, P. kluyveri Y1125, and P. kluyveri Y1164 using grape pomace extract as fermentation medium at $298.15 \mathrm{~K}$ and $1 \mathrm{~atm}$.

\begin{tabular}{|c|c|c|c|c|}
\hline Yeast & $\Delta H_{f}^{\text {cell }}\left(\mathbf{k J ~ C - m o l}{ }^{-\mathbf{1}}\right)$ & $\Delta H_{R X}^{O}\left(\mathbf{k J ~ C - m o l}{ }^{-\mathbf{1}}\right)$ & $-\Delta G_{R X}^{O}\left(\mathbf{k J ~ C - \mathbf { m o l } ^ { - 1 } )}\right.$ & $\Delta S_{R X}^{O}\left(\mathbf{k J ~ K}^{-1} \mathrm{C}-\mathrm{mol}^{-1}\right)$ \\
\hline C pyralidae Y1117 & -193.22 & -5006.75 & -5141.07 & -0.45 \\
\hline P. kluyveri Y1125 & -138.463 & -5160.48 & -5223.87 & -0.21 \\
\hline P. kluyveri Y1164 & -195.23 & -8283.54 & -8441.26 & -0.53 \\
\hline
\end{tabular}

\section{Conclusions}

The stoichiometric models and bioenergetic parameters analyzed in this study do not necessarily indicate the potential of the yeast or the process to produce biopreservatives but illustrate biochemical conversion of substrates needed for growth and production of secondary metabolites. Furthermore, this study does not report on the optimization of biopreservation production, but rather maximizing the consumption of agro-waste material. For an adequate biochemical system design for biopreservative production by non-Saccharomyces yeasts, important engineering and biological aspects are always needed. This has been successfully addressed by the outcome of this work, whereby numerous stoichiometric and bioenergetic parameters were determined. The biological stoichiometric models have been effectively developed, which accounted for mass and part of the energy balances required for simulation of industrial-scale production of biopreservatives using cheaply available, renewable agro-waste as raw material. The key parameters presented in this work can be used in prediction of performance as well as the feasibility of metabolic reactions during industrial-scale production of biopreservatives from biocontrol yeasts. Additionally, the model and bioenergetics data reported are only applicable to the yeast strains used in this study. This work is the first to report on biological stoichiometry and bioenergetics during biochemical conversion of substrate and secondary metabolite production (biopreservatives) by non-Saccharomyces yeasts using grape pomace extract as fermentation medium. Future studies should be undertaken using other agro-waste or substrate sources and compared to the data generated by this study.

Author Contributions: Conceptualization, M.M.-N., H.W.d.P. and B.S.C.; methodology and software, M.M.-N., S.K.O.N. and B.S.C.; validation, S.K.O.N., H.W.d.P., V.I.O. and N.P.J.; formal analysis, M.M.-N., E.A.A. and U.F.H.; investigation, M.M.-N. and U.F.H.; resources, N.P.J., H.W.d.P. and S.K.O.N.; data curation, B.S.C., M.M.-N., V.I.O. and E.A.A.; writing-original draft preparation, M.M.-N.; visualization, review and editing, S.K.O.N., H.W.d.P., N.P.J., V.I.O., E.A.A. and U.F.H.; supervision, S.K.O.N., H.W.d.P. and N.P.J.; project administration, N.P.J., H.W.d.P. and S.K.O.N.; funding acquisition, N.P.J., H.W.d.P. and S.K.O.N. All authors have read and agreed to the published version of the manuscript.

Funding: The financial support was provided by the National Research Foundation (NRF) (Grant 117833), the Agricultural Research Council (ARC) of South Africa, and the Bioresource Engineering Research Group (BioERG).

Institutional Review Board Statement: Not applicable.

Informed Consent Statement: Not applicable as this study did not involve humans.

Acknowledgments: The authors would like to thank the Agricultural Research Council (ARC), the National Research Foundation (NRF), and the Bioresource Engineering Research Group (BioERG), Department of Biotechnology, Cape Peninsula University of Technology, for funding and infrastructure. The authors thank all students, interns, technicians, and research assistants who contributed. The grant holders acknowledge that opinions, findings and conclusions or recommendations expressed in this publication, are those of the authors, and that the NRF accepts no liability whatsoever in this regard. The funding body had no involvement in the following aspects: study design; collection, analysis and interpretation of data; writing of the manuscript; decision to publish the work.

Conflicts of Interest: The authors hereby declare that they have no conflict of interest. 


\section{References}

1. Ciani, M.; Fatichenti, F. Killer Toxin of Kluyveromyces Phaffii DBVPG 6076 as a Biopreservative Agent To Control Apiculate Wine Yeasts. Appl. Environ. Microbiol. 2001, 67, 3058-3063. [CrossRef] [PubMed]

2. Gürakan, G.C. Biopreservation by Lactic Acid Bacteria. In Metabolism and Applications of Lactic Acid Bacteria; Özer, B., Ed.; Research Signpost: Trivandrum, India, 2007; pp. 15-31.

3. Nally, M.C.; Pesce, V.M.; Maturano, Y.P.; Assaf, L.R.; Toro, M.E.; de Figueroa, L.C.; Vazquez, F. Antifungal Modes of Action of Saccharomyces and Other Biocontrol Yeasts against Fungi Isolated from Sour and Grey Rots. Int. J. Food Microbiol. 2015, 204, 91-100. [CrossRef] [PubMed]

4. Nadai, C.; Junior, W.J.F.L.; Favaron, F.; Giacomini, A.; Corich, V. Biocontrol Activity of Starmerella Bacillaris yeast against Blue Mold Disease on Apple Fruit and Its Effect on Cider Fermentation. PLoS ONE 2018, 13, e0204350. [CrossRef] [PubMed]

5. Abbey, J.A.; Percival, D.; Abbey, L.; Asiedu, S.K.; Prithiviraj, B.; Schilder, A. Biofungicides as Alternative to Synthetic Fungicide Control of Grey Mould (Botrytis Cinerea)-Prospects and Challenges. Biocontrol Sci. Technol. 2019, 29, 207-228. [CrossRef]

6. Mewa-Ngongang, M.; du Plessis, H.W.; Ntwampe, S.K.; Chidi, B.S.; Hutchinson, U.F.; Mekuto, L.; Jolly, N.P. Grape Pomace Extracts as Fermentation Medium for the Production of Potential Biopreservation Compounds. Foods 2019, 8, 51. [CrossRef] [PubMed]

7. von Stockar, U.; Vojinović, V.; Maskow, T.; Liu, J. Can Microbial Growth Yield Be Estimated Using Simple Thermodynamic Analogies to Technical Processes? Chem. Eng. Process. Process Intensif. 2008, 47, 980-990. [CrossRef]

8. Duboc, P.; Marison, I.; Von Stockar, U. Quantitative Calorimetry and Biochemical Engineering. Handb. Therm. Anal. Calorim. 1999, 4, 267-365.

9. Liu, J.-S.; Vojinović, V.; Patiño, R.; Maskow, T.; von Stockar, U. A Comparison of Various Gibbs Energy Dissipation Correlations for Predicting Microbial Growth Yields. Thermochim. Acta 2007, 458, 38-46. [CrossRef]

10. Heijnen, J.J. Impact of Thermodynamic Principles in Systems Biology. In Biosystems Engineering II; Springer: Berlin/Heidelberg, Germany, 2010; pp. 139-162.

11. Akinpelu, E.A.; Ntwampe, S.K.O.; Chen, B.-H. Biological Stoichiometry and Bioenergetics of Fusarium Oxysporum EKT01/02 Proliferation Using Different Substrates in Cyanidation Wastewater. Can. J. Chem. Eng. 2018, 96, 537-544. [CrossRef]

12. Battley, E.H. A Comparison of Energy Changes Accompanying Growth Processes by Saccharomyces Cerevisiae. J. Therm. Anal. Calorim. 2011, 104, 193-200. [CrossRef]

13. Battley, E.H. A Theoretical Study of the Thermodynamics of Microbial Growth Using Saccharomyces Cerevisiae and a Different Free Energy Equation. Q. Rev. Biol. 2013, 88, 69-96. [CrossRef] [PubMed]

14. Mewa-Ngongang, M.; du Plessis, H.W.; Hutchinson, U.F.; Mekuto, L.; Ntwampe, S.K. Kinetic Modelling and Optimisation of Antimicrobial Compound Production by Candida Pyralidae KU736785 for Control of Candida guilliermondii. Food Sci. Technol. Int. 2017, 23, 358-370. [CrossRef] [PubMed]

15. Thornton, W.M. XV. The Relation of Oxygen to the Heat of Combustion of Organic Compounds. Lond. Edinb. Dublin Philos. Mag. J. Sci. 1917, 33, 196-203. [CrossRef] 